\title{
FORECASTING STOCK MARKET VOLATILITY: EVIDENCE FROM FOURTEEN COUNTRIES
}

\author{
ERCAN BALABAN
}

Deniz Yatırım Securities, Istanbul 80496 Turkey

Johann Wolfgang Goethe University, Frankfurt/M. 60325 Germany

e-mail: ercan.balaban@denizyatirim.com.

ASLI BAYAR

Department of Management

Bilkent University, Ankara 06533 Turkey

Tel.: + 903122902046

Fax: + 903122664958

e-mail: bayar@bilkent.edu.tr

\section{Key Words:}

Stock market volatility, forecasting, forecast evaluation

\begin{abstract}
This paper evaluates the out-of-sample forecasting accuracy of seven models for weekly volatility in fourteen stock markets. Volatility is defined as within-week standard deviation of continuously compounded daily returns on the stock market index of each country for the period December 1987 to December 1997. Total volatility series include 522 weeks. The first half of the sample (261 weeks) is retained for the estimation of parameters while the second half is for the forecast period. The following models are employed: a random walk model, a historical mean model, moving average models, weighted moving average models, exponentially weighted moving average models, an exponential smoothing model, and a regression model. We first use the standard loss functions to evaluate the performance of the competing models: the mean error, the mean absolute error, the root mean squared error, and the mean absolute percentage error. We also employ the asymmetric loss functions to penalise under/over-prediction.
\end{abstract}

JEL Classification: C22; C53; G12; G1

\section{INTRODUCTION}

The financial economic research has no consensus on the relative quality of volatility forecasts in the financial markets. Different studies recommend different forecasting methods. For example, in forecasting volatility of stock exchange markets, Tse (1991), and Tse and Tung (1992) favour exponential weighted moving average model in Japan and Singapore. However, Dimson and Marsh (1990) analysing the U.S. equity market show superiority of simple regression and exponential smoothing models. 
B railsford and Faff (1996) investigate the out-of-sample predictive ability of several models of stock market volatility in A ustralia. In the measurement of the performance of the models, in addition to symmetric loss functions, they use asymmetric loss functions to penalise under/over prediction. They conclude that the $\mathrm{ARCH}$ class of models and a simple regression model provide superior forecast of the volatility. However, the various model ranking are shown to be sensitive to the error statistics used to assess the accuracy of the forecasts.

On the other hand, The evidence with respect to foreign exchange markets is presented by West and Cho (1995), Brooks and Burke (1998), and Balaban (1999). West and Cho (1995) can not show superiority of any forecasting models.

In the finance literature, the existing evidence about the relative quality of volatility forecasts is related to an individual country's stock market: the USA (A kgiray, 1989), the UK (Dimson and Marsh, 1990), Japan (Tse, 1991), Singapore (Tse and Tung, 1992), A ustralia (Brailsford and Faff, 1996), Switzerland (A djaoute, Bruand and Gibson-A sner, 1998), Turkey (Balaban, 1998). M oreover, most of the previous researches focus on the forecasting monthly stock market volatility. The present study is primarily based on Brailsford and Faff (1996), and provides an international evidence from fourteen countries with respect to weekly stock market volatility.

The rest of the paper is organised as follows: In the second section, data and methodology are described, in the third section empirical results are presented, and finally in the fourth section the paper is concluded.

\section{DATA AND METHODOLOGY}

We employ daily observations of stock market indices of fourteen countries for the period December 1987 to December 1997. The data have been obtained from Datastream, and the investigated countries (indices) are Belgium (Brussels All Shares Price Index), Canada (Toronto SE 300 Composite Price Index), Denmark (Copenhagen SE General Price Index), Finland (Hex General Price Index), Germany (Faz General Price Index), Hong Kong (Hang Seng Price Index), Italy (M ilan Comit General Price Index), Japan (Nikkei 500 Price Index), the N etherlands (CBS A II Share General Price Index), the Philippines (Philippines SE Composite Price Index), Singapore (Singapore All Share Price Index), Thailand (Bangkok S.E.T. Price Index), the UK (FTSE All Share Index) and the USA (NY SE Composite Index). The continuously compounded weekly returns are calculated as follows:

$$
\begin{gathered}
R_{w, t}=\ln \left(I_{w, t} / I_{w, t-1}\right) \\
\sigma_{a, w}=\left[\frac{1}{(n-1)} \sum_{t=1}^{n}\left(R_{w, t}-\mu_{w}\right)^{2}\right]^{0.5}
\end{gathered}
$$

where $I_{w, t}$ and $R_{w, t}$ denote the value of stock market index and continuously compounded return on trading day $t$ in week $w$, respectively. We define weekly realised volatility as the within-week standard deviation of continuously compounded weekly returns as follows:

$$
\mu_{w}=(1 / n) \sum_{t=1}^{n} R_{w, t}
$$


M ean daily index return and within-week standard deviation of daily returns in week $w$ are respectively shown by $\mu_{w}$ and $\sigma_{a, w}$. The number of trading days in a week is given by $n$. In the data set for each country there are 522 weekly volatility observations. In the analysis, first 261 of the observations from December 1987 to November 1992 are used for estimation, and the second 261 observations from December 1992 to December 1997 are used for forecasting. In the Table 1 summary statistics for within-week standard deviations of returns in whole period, estimation period, and forecast period are presented. The table shows that in four countries, Canada, Finland, Hong K ong and Italy, standard deviations in forecast period are higher than estimation period. In most of the countries, in the forecast period, standard deviations decline.

Table 1. SUMMARY STATISTICS: Within-Week Standard Deviations

\begin{tabular}{|c|c|c|c|c|c|c|c|c|c|c|c|c|}
\hline & \multicolumn{4}{|c|}{ Whole Period } & \multicolumn{4}{|c|}{ Estimation Period } & \multicolumn{4}{|c|}{ Forecast Period } \\
\hline & M ean & $\begin{array}{c}\text { Standard } \\
\text { Dev. }\end{array}$ & Skewness & Kurtosis & M ean & \begin{tabular}{|c} 
Standard \\
Dev.
\end{tabular} & & Kurtosis & M ean & $\begin{array}{c}\text { Standard } \\
\text { Dev. }\end{array}$ & & Kurtosis \\
\hline BEL & 0.0051 & 0.0039 & 2.6991 & 13.4987 & 0.0054 & 0.0047 & 2.3840 & 10.2340 & 0.0048 & 0.0029 & 2.6700 & 15.99 \\
\hline CAN & 0.0048 & 0.00 & & 25.10 & 48 & 0.0026 & & & 0.0049 & & & \\
\hline DEN & 0.0050 & 0.00 & & 30.52 & 51 & & & & 0.0048 & & & \\
\hline FIN & 0.0084 & & & 18.91 & 65 & & & & & & & \\
\hline GER & 0.0086 & 0.00 & & 45.46 & 0.0095 & & & 10 & 0078 & & & 200 \\
\hline HON & 0118 & & & 45.1534 & 0.0105 & & & 55.37 & 132 & & & 38.9700 \\
\hline ITAL & 0.0097 & 0.0057 & & 14.1141 & 0.0087 & & & 11.2360 & 0.0107 & 0.0053 & & 20.2300 \\
\hline JAP & 0.0089 & 0.0067 & & 11.0324 & 0.0094 & & & 9.0240 & 0.0083 & 0.0052 & & 9.9600 \\
\hline NET & 0.0071 & 0.0043 & 2.4407 & 12.3680 & 0.0071 & 0.0 & 2.4080 & 11.5750 & 0.0070 & 0.0043 & & 13.1400 \\
\hline PHI & 0.0126 & 0.0 & & 5.3678 & 0.0142 & & 1.1 & 4.6120 & 0.0110 & 0.0067 & & 6.6500 \\
\hline SNG & 0.0074 & 0.0056 & 3.1548 & 17.6716 & 0.0074 & 0.0062 & 3.2390 & 17.8920 & 0.0073 & 0.0051 & 500 & 14.9000 \\
\hline THA & 0128 & 0.0091 & 2.0638 & 8.5456 & 0.0129 & & 2.1110 & 8.2760 & 0.0127 & 0.0078 & & 6.8700 \\
\hline UK & 0.0063 & 0.0032 & 2.26 & 11.9167 & 0.0071 & & 2.2840 & 10.5610 & 0.0055 & 0.0024 & 1.6300 & 9.7100 \\
\hline US & 0.0064 & 0.0039 & 2.9443 & 20.3649 & 0.0073 & 0.0041 & 2.4200 & 13.8160 & 0.0056 & 0.0036 & 4.0100 & 35.5700 \\
\hline
\end{tabular}

Whole period includes the whole sample (522 weeks).

Estimation period covers the first 216 observations.

Forecast period covers the second 216 weeks.

The following models are employed as forecast competitors:

\section{a) Random walk model:}

This model says that the best forecast of this week's volatility is the last week's realised volatility.

$$
\sigma_{f, w}(R W)=\sigma_{f, w-1}
$$

where $w=262, \ldots, 522$.

\section{b) Historical mean model:}

According to this model, the best forecast of this week is average of all past observations available.

$$
\sigma_{f, w}(H M)=\frac{1}{w-1} \sum_{j=1}^{w-1} \sigma_{a, j}
$$

where $\mathrm{w}=262, \ldots, 522$. 


\section{c) Moving average (MA- $\alpha)$ model:}

This model says that the best forecast of this week's volatility is equally weighted average of realised volatilities in the last $\alpha$ weeks.

$$
\sigma_{f, w}(M A(\alpha))=\frac{1}{\alpha} \sum_{j=1}^{\alpha} \sigma_{a, w-j}
$$

where $w=262, \ldots, 522$, and $\alpha=4,6,12,24,36,52$. The (arbitrarily) chosen values of $\alpha$ represent different horizons from the very short to the long terms.

\section{d) Weighted moving average (WMA- $\alpha$ ) model:}

In the WMA- $\alpha$ model, weight of each observation is not equal like in MA- $\alpha$ model (Liljeblom and Stenius (1997))

$$
\sigma_{f, w}(W M A(\alpha))=\sum_{j=1}^{\alpha} \lambda_{i} \sigma_{a, w-j}
$$

where $w=262, \ldots, 522$, and $\alpha=4,6,12,24,36,52$.

In the equation (7), the weight of each observation, $\lambda_{i}$, declines by $10 \%$, giving the highest (lowest) weight to the newest (oldest) information.

\section{e) Exponentially smoothing (ES) model:}

In the ES model, the forecast of volatility is a function of the immediate past forecast and the immediate past observed volatility (Dimson and Marsh (1990); Brailsford and Faff (1996)).

$$
\sigma_{f, w}(E S)=\theta \sigma_{f, w-1}(E S)+(1-\theta) \sigma_{a, w-1}
$$

where $\mathrm{w}=262, \ldots, 522$.

The smoothing parameter $(\theta)$ is restricted to lie between zero and one. Following the previous research, we determine the optimal value of $\theta$ empirically. To this end, we start an initial value of $\theta$, zero in our case, and increase it by 0.01 each time until we obtain unity for $q$ ((Brailsford and Faff (1996)).

\section{f) Exponentially weighted moving average (EWMA- $\alpha$ ) model:}

In this model, the past observed volatility is replaced by the $\alpha$-week moving average forecast; ie., the forecast of the M A- $\alpha$ model (T se, 1991; T se and Tung, 1992; and B railsford and Faff, 1996).

$$
\sigma_{f, w}(E W M A-\alpha)=\lambda \sigma_{f, w-1}(E W M-\alpha)+(1-\lambda) \sigma_{a, w}(M A-\alpha)
$$

where $w=262, \ldots, 522$, and $\alpha=4,6,12,24,36,52$. Similar to the MA- $\alpha$ models, the (arbitrarily) chosen values represent different horizons from the very short to the long terms. 


\section{g) Regression (REG) model:}

W e first run the regression below for the sample where w is between one and 261 .

$$
\sigma_{a, w}=c+\beta \sigma_{a, w-1}+u_{w-1}
$$

Then we construct the forecast for the first week of the forecast period ( $w=262$ ) using the estimated regression parameters:

$$
\sigma_{f, w}(R E G)=c+\beta \sigma_{a, w-1}
$$

W e update the regression equation weekly; ie., each week we drop the oldest observation and add the last or newest observation. Thus we use the same number of observations in each case. Hence for each country the total estimation procedure requires estimation of 261 regressions to obtain out-of-sample forecasts of w eekly volatility. $N$ ote that this procedure lets us depend on the time-varying parameters for each forecast.

\section{FORECAST EVALUATION AND EMPIRICAL RESULTS}

We compare the forecast performance of each model through both symmetric and asymmetric error statistics.

\section{a) Symmetric Error Statistics}

Four commonly used loss functions or error statistics: the mean error (ME), the mean absolute error (MAE), the root mean squared error (RMSE), and the mean absolute percentage error (MAPE) are employed to measure the performance of the forecasting models.

$$
\begin{gathered}
M E=\frac{1}{261} \sum_{m=262}^{522}\left(\sigma_{f, w}-\sigma_{a, w}\right) \\
M A E=\frac{1}{261} \sum_{m=262}^{522}\left|\sigma_{f, w}-\sigma_{a, w}\right| \\
R M S E=\left[\frac{1}{261} \sum_{m=262}^{522}\left(\sigma_{f, w}-\sigma_{a, w}\right)^{2}\right]^{0.5} \\
M A P E=\frac{1}{261} \sum_{m=262}^{522}\left|\frac{\sigma_{f, w}-\sigma_{a, w}}{\sigma_{a, w}}\right|^{2}
\end{gathered}
$$

$\sigma_{f, w}$ and $\sigma_{a, w}$ denote the volatility forecast and the realised volatility in week $w$, respectively. 
Table 2, Table 3, Table 4, and Table 5 provide results of forecast error statistics for each model according to symmetric error measures, (ME, MAE, RMSE, and MAPE respectively).

Table 2 illustrates that according to ME criteria, EWMA and ES model under-predict the volatility in all of the stock markets. Moreover, except for $H M$ and REG, all models under-predict the volatility in most of the stock markets.

Table 2:

\begin{tabular}{|c|c|c|c|c|c|c|c|}
\hline & RW & HM & MA-12 & WMA-12 & EWMA-12 & ES & REG \\
\hline BEL & -0.009 & 0.241 & -0.120 & -0.101 & -0.236 & -0.240 & 0.152 \\
\hline CAN & -0.034 & -0.228 & -0.160 & -0.132 & -0.211 & -0.210 & -0.219 \\
\hline DEN & 0.025 & 0.243 & -0.006 & -0.044 & -0.096 & -0.010 & 0.230 \\
\hline FIN & 0.044 & -2.700 & -0.005 & -0.032 & -0.131 & -0.130 & -1.776 \\
\hline GER & -0.041 & 1.023 & -0.210 & -0.177 & -0.321 & -0.320 & 0.785 \\
\hline HON & -0.032 & -1.814 & -0.600 & -0.479 & -0.020 & -0.002 & -1.192 \\
\hline ITAL & 0.014 & -1.257 & 0.001 & 0.012 & -0.246 & -0.250 & -0.905 \\
\hline JAP & -0.089 & 0.671 & -0.270 & -0.238 & -0.274 & -0.270 & 0.257 \\
\hline NET & -0.042 & -0.326 & -0.270 & -0.222 & -0.309 & -0.310 & -0.215 \\
\hline PHI & -0.028 & 2.142 & -0.310 & -0.249 & -0.347 & -0.350 & 1.419 \\
\hline SNG & -0.044 & -0.064 & -0.230 & -0.182 & -0.277 & -0.280 & -0.043 \\
\hline THA & -0.017 & -0.188 & -0.130 & -0.095 & -0.301 & -0.300 & -0.105 \\
\hline UK & -0.006 & 1.137 & -0.005 & -0.048 & -0.133 & -0.130 & 0.791 \\
\hline US & -0.019 & 0.945 & -0.200 & -0.165 & -0.310 & -0.310 & 0.675 \\
\hline
\end{tabular}

Results of MAE in Table 3 indicate that in ranking, $\mathrm{HW}$ gives the second worst results in the forecasting, after RW model. However, ES model gives the most accurate forecasts. In 12 countries, ES model is the best model. In the other countries, Canada and Hong Kong, REG and WMA-12 are the best models respectively. In general ranking, WMA-12 provides the second best forecast. MA-12, EWMA-12 and REG models rank third, fourth and fifth respectively.

As shown in Table 4, according to RMSE criteria, ES model is the best performing model. On the other hand, RW model provides the worst forecasts in 12 countries. For the other countries, Hong Kong and the Netherlands, HM is the worst model. In ranking, W M A-12 and M A-12 are again the second and the third best models respectively.

Finally, Table 5 shows the results according to MAPE criteria, like under previous criterias, ES model gives relatively more accurate results than the other models. However, according to MAPE, even though in general $\mathrm{HM}$ is the second least performing model, it gives the best results in two countries, Finland and I taly.

In summary, ES model is consistently the best performing model according to $M A E$, RMSE, and MAPE. On the other hand, $H M$ is the least performing model when MAE, and RM SE are used, and it is the second least performing one when M APE is used.

In all of the countries, except in Finland, Italy, the Netherlands, Singapore, and the US, symmetric error statistics provide quite consistent results for the performance of the models. 
Table 3:

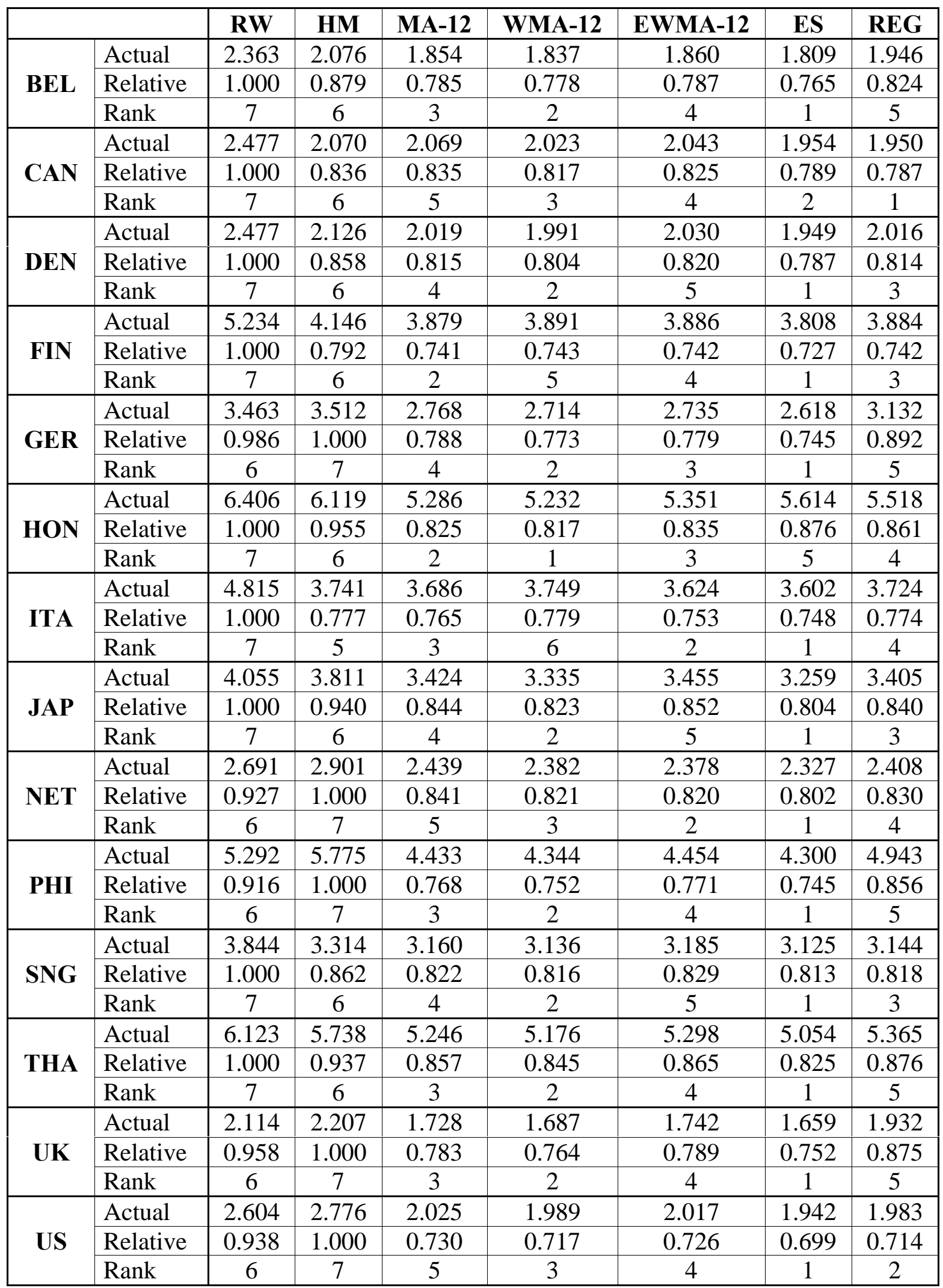


Table 4. RMSE

\begin{tabular}{|c|c|c|c|c|c|c|c|c|}
\hline & & $\mathbf{R W}$ & HM & MA-12 & WMA-12 & EWMA-12 & ES & REG \\
\hline \multirow{3}{*}{ BEL } & A ctual & 3.334 & 2.958 & 2.659 & 2.658 & 2.688 & 2.647 & 2.762 \\
\hline & Relative & 1.000 & 0.887 & 0.798 & 0.797 & 0.806 & 0.794 & 0.828 \\
\hline & Rank & 7 & 6 & 3 & 2 & 4 & 1 & 5 \\
\hline \multirow{3}{*}{ CAN } & A ctual & 3.892 & 3.267 & 3.235 & 3.187 & 3.220 & 3.130 & 3.140 \\
\hline & Relative & 1.000 & 0.839 & 0.831 & 0.819 & 0.827 & 0.804 & 0.807 \\
\hline & Rank & 7 & 6 & 5 & 3 & 4 & 1 & 2 \\
\hline \multirow{3}{*}{ DEN } & A ctual & 3.899 & 3.379 & 3.256 & 3.239 & 3.278 & 3.211 & 3.230 \\
\hline & Relative & 1.000 & 0.867 & 0.835 & 0.831 & 0.841 & 0.824 & 0.828 \\
\hline & Rank & 7 & 6 & 4 & 3 & 5 & 1 & 2 \\
\hline \multirow{3}{*}{ FIN } & A ctual & 7.43 & 6.556 & 5.892 & 5.879 & 5.902 & 5.835 & 6.117 \\
\hline & Relative & 1.000 & 0.882 & 0.793 & 0.791 & 0.794 & 0.785 & 0.823 \\
\hline & Rank & 7 & 6 & 3 & 2 & 4 & 1 & 5 \\
\hline \multirow{3}{*}{ GER } & A ctual & 5.101 & 4.836 & 4.242 & 4.198 & 4.272 & 4.154 & 4.462 \\
\hline & Relative & 1.000 & 0.948 & 0.832 & 0.823 & 0.837 & 0.814 & 0.875 \\
\hline & Rank & 7 & 6 & 3 & 2 & 4 & 1 & 5 \\
\hline \multirow{3}{*}{ HON } & A ctual & 10.797 & 11.018 & 9.697 & 9.591 & 9.719 & 9.664 & 9.708 \\
\hline & Relative & 0.980 & 1.000 & 0.880 & 0.870 & 0.882 & 0.877 & 0.881 \\
\hline & Rank & 6 & 7 & 3 & 1 & 5 & 2 & 4 \\
\hline \multirow{3}{*}{ ITA } & A ctual & 6.750 & 5.476 & 5.153 & 5.166 & 5.176 & 5.109 & 5.329 \\
\hline & Relative & 1.000 & 0.811 & 0.763 & 0.765 & 0.767 & 0.757 & 0.789 \\
\hline & Rank & 7 & 6 & 2 & 3 & 4 & 1 & 5 \\
\hline \multirow{3}{*}{ JAP } & A ctual & 5.634 & 5.222 & 4.874 & 4.763 & 4.915 & 4.686 & 4.818 \\
\hline & Relative & 1.000 & 0.927 & 0.865 & 0.845 & 0.872 & 0.832 & 0.855 \\
\hline & Rank & 7 & 6 & 4 & 2 & 5 & 1 & 3 \\
\hline \multirow{3}{*}{ NET } & A ctual & 3.776 & 4.324 & 3.452 & 3.387 & 3.472 & 3.329 & 3.520 \\
\hline & Relative & 0.873 & 1.000 & 0.798 & 0.783 & 0.803 & 0.770 & 0.814 \\
\hline & Rank & 6 & 7 & 3 & 2 & 4 & 1 & 5 \\
\hline \multirow{3}{*}{ PHI } & A ctual & 7.198 & 7.083 & 6.082 & 6.001 & 6.129 & 6.007 & 6.282 \\
\hline & Relative & 1.000 & 0.984 & 0.845 & 0.834 & 0.851 & 0.835 & 0.873 \\
\hline & Rank & 7 & 6 & 3 & 1 & 4 & 2 & 5 \\
\hline \multirow{3}{*}{ SNG } & A ctual & 5.611 & 5.068 & 4.730 & 4.734 & 4.819 & 4.756 & 4.720 \\
\hline & Relative & 1.000 & 0.903 & 0.843 & 0.844 & 0.859 & 0.848 & 0.841 \\
\hline & Rank & 7 & 6 & 2 & 3 & 5 & 4 & 1 \\
\hline \multirow{3}{*}{ THA } & A ctual & 8.447 & 7.843 & 7.251 & 7.134 & 7.333 & 7.065 & 7.164 \\
\hline & Relative & 1.000 & 0.928 & 0.858 & 0.845 & 0.868 & 0.836 & 0.848 \\
\hline & Rank & 7 & 6 & 4 & 2 & 5 & 1 & 3 \\
\hline \multirow{3}{*}{ UK } & A ctual & 2.752 & 2.720 & 2.320 & 2.278 & 2.329 & 2.251 & 2.435 \\
\hline & Relative & 1.000 & 0.988 & 0.843 & 0.828 & 0.846 & 0.818 & 0.885 \\
\hline & Rank & 7 & 6 & 3 & 2 & 4 & 1 & 5 \\
\hline \multirow{3}{*}{ US } & A ctual & 3.940 & 3.774 & 3.211 & 3.192 & 3.203 & 3.168 & 2.513 \\
\hline & Relative & 1.000 & 0.958 & 0.815 & 0.810 & 0.813 & 0.804 & 0.638 \\
\hline & Rank & 7 & 6 & 5 & 3 & 4 & 2 & 1 \\
\hline
\end{tabular}

The root mean squared error, (RM SE ), actual figures must be multiplied by $10^{-2}$. 
Table 5. MAPE



The mean absolute percentage error, (M APE), actual figures must be multiplied by $10^{-2}$. 


\section{b) Asymmetric Error Statistics}

These conventional error statistics used in the previous subsection, ME, MAE, RM SE, and MAPE, are symmetric; ie., they give an equal weight to under-and-over-predictions of volatility of similar magnitude. However, many investors do not give equal importance to under and over prediction of volatility, Especially, in the pricing of the options, while underprediction of volatility is undesirable for a seller, overprediction of it is undesirable for a buyer. Following Pagan and Schwert (1990) and Brailsford and Faff (1996), to penalise under(over)-predictions more heavily, the following mean mixed error statistics are constructed:

$$
\begin{aligned}
& \operatorname{MME}(U)=\frac{1}{261}\left[\sum_{t=1}^{O}\left|\sigma_{f, w}-\sigma_{a, w}\right|+\sum_{t=1}^{U} \sqrt{\left|\sigma_{f, w}-\sigma_{a, w}\right|}\right] \\
& \operatorname{MME}(O)=\frac{1}{261}\left[\sum_{t=1}^{O} \sqrt{\left|\sigma_{f, w}-\sigma_{a, w}\right|}+\sum_{t=1}^{U}\left|\sigma_{f, w}-\sigma_{a, w}\right|\right]
\end{aligned}
$$

where $O$ is the number of over-predictions, and $U$ is the number of under-predictions. $M M E(U)$ and $M M E(O)$ penalise the under-predictions and over-predictions more heavily, respectively.

It is expected that for an "unbiased" forecast model under and overprediction number should be equal to $50 \%$ of the time, ie. $50 \%$ of the time it underpredicts, and $50 \%$ of the time it overpredicts.

Results in Table 6 show that, except for RW, HM, and REG models, all of the models overpredict the volatility in all of the stock markets. However, among RW, HM, and REG, even though HM and REG overpredicts the volatility in 12 countries, RW over predicts the volatility only in 6 countries, ie. RW underpredicts in most of the countries. These results proved by $M M E$ conflict with the results provided by $M E$. The reason for the difference in the results can be explained as $\mathrm{MME}$ takes into account only the number of under and overpredictions, however for ME magnitude of the error is important. Thus for the difference it can be said that the models overpredict the volatility most of the time, but their forecast error are small.

If underprediction of the model is undesirable, HW is the best, and REG is the worst model. However, when the results for US is evaluated, it is observed that REG is an extreamly bad model for forecasting volatility of US market. If we drop the results for the US, and re-rank the models, REG is the best model, RW is the worst model, and HM is the third best model after W M A-12.

On the other hand, if overprediction is undesirable in the forecasting, ES model performs the best, and RW performs the worst. However, in this case, when we do not take into account the results for US, ranking does not change much, ranking of REG declines just from seven to six, and ES model is still the best model. A ccording to $M M E(0), W M A-12$ provides the third best performance after EW M A-12. 
Table 6a. MMEU and MMEO

\begin{tabular}{|c|c|c|c|c|c|c|c|c|c|}
\hline & & & RW & HM & MA-12 & WMA-12 & EWMA-12 & ES & REG \\
\hline \multirow{8}{*}{ BEL } & & A ctual & 2.269 & 1.682 & 1.949 & 1.922 & 2.024 & 2.003 & 1.705 \\
\hline & $\operatorname{MME}(\mathrm{U})$ & Relative & 1.000 & 0.741 & 0.859 & 0.847 & 0.892 & 0.883 & 0.752 \\
\hline & & Rank & 7 & 1 & 4 & 3 & 6 & 5 & 2 \\
\hline & & A ctual & 2.347 & 2.674 & 2.104 & 2.099 & 2.064 & 1.983 & 2.508 \\
\hline & $\operatorname{MME}(\mathbf{O})$ & Relative & 0.878 & 1.000 & 0.787 & 0.785 & 0.772 & 0.741 & 0.938 \\
\hline & & Rank & 5 & 7 & 4 & 3 & 2 & 1 & 6 \\
\hline & $\%$ & Underestimaton & 48.3 & 36.8 & 45.6 & 44.4 & 45.6 & 47.9 & 37.2 \\
\hline & $\%$ & Overestimation & 51.7 & 63.2 & 54.4 & 55.6 & 54.4 & 52.1 & 62.8 \\
\hline \multirow{8}{*}{ CAN } & & A ctual & 2.308 & 1.958 & 1.953 & 1.915 & 2.029 & 1.935 & 1.919 \\
\hline & $\operatorname{MME}(\mathbf{U})$ & Relative & 1.000 & 0.848 & 0.846 & 0.830 & 0.879 & 0.838 & 0.832 \\
\hline & & Rank & 7 & 5 & 4 & 1 & 6 & 3 & 2 \\
\hline & & A ctual & 2.308 & 2.318 & 2.357 & 2.321 & 2.251 & 2.209 & 2.211 \\
\hline & MME(O) & Relative & 0.979 & 0.984 & 1.000 & 0.985 & 0.955 & 0.937 & 0.938 \\
\hline & & Rank & 4 & 5 & 7 & 6 & 3 & 1 & 2 \\
\hline & $\%$ & Underestimaton & 50.6 & 40.2 & 40.2 & 40.6 & 42.1 & 41.8 & 42.1 \\
\hline & $\%$ & Overestimation & 49.4 & 59.8 & 59.8 & 59.4 & 57.9 & 58.2 & 57.9 \\
\hline \multirow{8}{*}{ DEN } & & A ctual & 2.280 & 1.632 & 1.893 & 1.874 & 1.920 & 1.869 & 1.592 \\
\hline & $\operatorname{MME}(\mathbf{U})$ & Relative & 1.000 & 0.716 & 0.830 & 0.822 & 0.842 & 0.820 & 0.698 \\
\hline & & R ank & 7 & 2 & 5 & 4 & 6 & 3 & 1 \\
\hline & & A ctual & 2.374 & 2.740 & 2.320 & 2.286 & 2.302 & 2.222 & 2.643 \\
\hline & $\operatorname{MME}(\mathbf{O})$ & Relative & 0.867 & 1.000 & 0.847 & 0.834 & 0.840 & 0.811 & 0.965 \\
\hline & & Rank & 5 & 7 & 4 & 2 & 3 & 1 & 6 \\
\hline & $\%$ & Underestimaton & 48.3 & 33.3 & 41.8 & 42.9 & 40.6 & 42.1 & 33.7 \\
\hline & $\%$ & Overestimation & 51.7 & 66.7 & 58.2 & 57.1 & 59.4 & 57.9 & 66.3 \\
\hline \multirow{8}{*}{ FIN } & & A ctual & 3.453 & 4.291 & 2.724 & 2.693 & 2.783 & 2.676 & 3.695 \\
\hline & MME(U) & Relative & 0.805 & 1.000 & 0.635 & 0.628 & 0.649 & 0.624 & 0.861 \\
\hline & & Rank & 5 & 7 & 3 & 2 & 4 & 1 & 6 \\
\hline & & A ctual & 3.639 & 1.817 & 3.272 & 3.323 & 3.214 & 3.229 & 2.261 \\
\hline & $\operatorname{MME}(\mathbf{O})$ & Relative & 1.000 & 0.499 & 0.899 & 0.913 & 0.883 & 0.887 & 0.621 \\
\hline & & Rank & 7 & 1 & 5 & 6 & 3 & 4 & 2 \\
\hline & $\%$ & U nderestimaton & 48.7 & 65.1 & 42.9 & 41.0 & 43.7 & 41.0 & 57.9 \\
\hline & $\%$ & Overestimation & 51.3 & 34.9 & 57.1 & 59.0 & 56.3 & 59.0 & 42.1 \\
\hline \multirow{8}{*}{ GER } & & A ctual & 2.776 & 1.845 & 2.349 & 2.313 & 2.403 & 2.345 & 1.796 \\
\hline & MME(U) & Relative & 1.000 & 0.665 & 0.846 & 0.833 & 0.866 & 0.845 & 0.647 \\
\hline & & Rank & 7 & 2 & 5 & 3 & 6 & 4 & 1 \\
\hline & & A ctual & 2.806 & 4.004 & 2.585 & 2.560 & 2.482 & 2.406 & 3.626 \\
\hline & MME(O) & Relative & 0.701 & 1.000 & 0.646 & 0.639 & 0.620 & 0.601 & 0.906 \\
\hline & & Rank & 5 & 7 & 4 & 3 & 2 & 1 & 6 \\
\hline & $\%$ & Underestimaton & 49 & 27.2 & 45.2 & 45.2 & 44.8 & 46.4 & 29.5 \\
\hline & $\%$ & Overestimation & 51 & 72.8 & 54.8 & 54.8 & 55.2 & 53.6 & 70.5 \\
\hline \multirow{8}{*}{ HON } & & A ctual & 3.792 & 3.769 & 3.192 & 3.132 & 3.241 & 3.303 & 3.446 \\
\hline & MME(U) & Relative & 1.000 & 0.994 & 0.842 & 0.826 & 0.855 & 0.871 & 0.909 \\
\hline & & Rank & 7 & 6 & 2 & 1 & 3 & 4 & 5 \\
\hline & & A ctual & 3.735 & 3.701 & 3.643 & 3.637 & 3.676 & 3.784 & 3.615 \\
\hline & MME(O) & Relative & 0.987 & 0.978 & 0.963 & 0.961 & 0.972 & 1.000 & 0.955 \\
\hline & & Rank & 6 & 5 & 3 & 2 & 4 & 7 & 1 \\
\hline & $\%$ & Underestimaton & 48.7 & 43.7 & 43.3 & 42.9 & 43.7 & 44.4 & 42.5 \\
\hline & $\%$ & Overestimation & 51.3 & 56.3 & 56.7 & 57.1 & 56.3 & 55.6 & 57.5 \\
\hline
\end{tabular}


Table 6b. MMEU and MMEO

\begin{tabular}{|c|c|c|c|c|c|c|c|c|c|}
\hline & & & RW & HM & MA-12 & WMA-12 & EWMA-12 & ES & REG \\
\hline \multirow{8}{*}{ ITA } & & A ctual & 3.443 & 3.467 & 2.746 & 2.809 & 2.746 & 2.813 & 3.291 \\
\hline & $\operatorname{MME}(\mathbf{U})$ & Relative & 0.993 & 1.000 & 0.792 & 0.810 & 0.792 & 0.811 & 0.949 \\
\hline & & Rank & 6 & 7 & 1 & 3 & 2 & 4 & 5 \\
\hline & & A ctual & 3.358 & 2.419 & 3.154 & 3.190 & 3.082 & 3.020 & 2.600 \\
\hline & MME(O) & Relative & 1.000 & 0.720 & 0.939 & 0.950 & 0.918 & 0.899 & 0.774 \\
\hline & & Rank & 7 & 1 & 5 & 6 & 4 & 3 & 2 \\
\hline & $\%$ & Underestimaton & 51.3 & 56.3 & 44.8 & 45.6 & 44.8 & 45.2 & 53.6 \\
\hline & $\%$ & Overestimation & 48.7 & 43.7 & 55.2 & 54.4 & 55.2 & 54.8 & 46.4 \\
\hline \multirow{8}{*}{ JAP } & & A ctual & 3.151 & 2.139 & 2.588 & 2.554 & 2.626 & 2.618 & 2.324 \\
\hline & MME(U) & Relative & 1.000 & 0.679 & 0.821 & 0.811 & 0.834 & 0.831 & 0.737 \\
\hline & & Rank & 7 & 1 & 4 & 3 & 6 & 5 & 2 \\
\hline & & A ctual & 2.982 & 3.890 & 3.024 & 2.960 & 3.009 & 2.808 & 3.254 \\
\hline & MME(O) & Relative & 0.767 & 1.000 & 0.777 & 0.761 & 0.773 & 0.722 & 0.836 \\
\hline & & Rank & 3 & 7 & 5 & 2 & 4 & 1 & 6 \\
\hline & $\%$ & Underestimaton & 51.7 & 30.7 & 41.4 & 42.1 & 41.8 & 45.6 & 38.7 \\
\hline & $\%$ & Overestimation & 48.3 & 69.3 & 58.6 & 57.9 & 58.2 & 54.4 & 61.3 \\
\hline \multirow{8}{*}{ NET } & & A ctual & 2.446 & 2.383 & 2.357 & 2.288 & 2.431 & 2.342 & 2.191 \\
\hline & $\operatorname{MME}(\mathbf{U})$ & Relative & 1.000 & 0.974 & 0.963 & 0.935 & 0.994 & 0.957 & 0.896 \\
\hline & & Rank & 7 & 5 & 4 & 2 & 6 & 3 & 1 \\
\hline & & A ctual & 2.458 & 2.745 & 2.364 & 2.364 & 2.179 & 2.254 & 2.482 \\
\hline & MME(O) & Relative & 0.896 & 1.000 & 0.861 & 0.861 & 0.794 & 0.821 & 0.904 \\
\hline & & Rank & 5 & 7 & 4 & 3 & 1 & 2 & 6 \\
\hline & $\%$ & Underestimaton & 48.7 & 41.8 & 48.3 & 46.7 & 47.9 & 48.7 & 43.3 \\
\hline & $\%$ & Overestimation & 51.3 & 58.2 & 51.7 & 53.3 & 52.1 & 51.3 & 56.7 \\
\hline \multirow{8}{*}{ PHI } & & A ctual & 3.560 & 2.412 & 3.059 & 2.999 & 3.093 & 3.030 & 2.363 \\
\hline & MME(U) & Relative & 1.000 & 0.677 & 0.859 & 0.842 & 0.869 & 0.851 & 0.664 \\
\hline & & Rank & 7 & 2 & 5 & 3 & 6 & 4 & 1 \\
\hline & & A ctual & 3.525 & 5.280 & 3.399 & 3.375 & 3.372 & 3.285 & 4.648 \\
\hline & MME(O) & Relative & 0.668 & 1.000 & 0.644 & 0.639 & 0.639 & 0.622 & 0.880 \\
\hline & & Rank & 5 & 7 & 4 & 3 & 2 & 1 & 6 \\
\hline & $\%$ & Underestimaton & 50.6 & 28.7 & 43.3 & 42.9 & 43.7 & 44.1 & 29.9 \\
\hline & $\%$ & Overestimation & 49.4 & 71.3 & 56.7 & 57.1 & 56.3 & 55.9 & 70.1 \\
\hline \multirow{8}{*}{ SNG } & & A ctual & 2.977 & 2.298 & 2.488 & 2.426 & 2.527 & 2.477 & 2.296 \\
\hline & $\operatorname{MME}(\mathbf{U})$ & Relative & 1.000 & 0.772 & 0.836 & 0.815 & 0.849 & 0.832 & 0.771 \\
\hline & & Rank & 7 & 2 & 5 & 3 & 6 & 4 & 1 \\
\hline & & A ctual & 2.921 & 3.203 & 2.847 & 2.874 & 2.814 & 2.821 & 3.054 \\
\hline & MME(O) & Relative & 0.912 & 1.000 & 0.889 & 0.897 & 0.879 & 0.881 & 0.954 \\
\hline & & Rank & 5 & 7 & 3 & 4 & 1 & 2 & 6 \\
\hline & $\%$ & Underestimaton & 51.3 & 36.4 & 42.9 & 41.8 & 44.4 & 42.5 & 39.8 \\
\hline & $\%$ & Overestimation & 48.7 & 63.6 & 57.1 & 58.2 & 55.6 & 57.5 & 60.2 \\
\hline \multirow{8}{*}{ THA } & & A ctual & 3.862 & 3.222 & 3.231 & 3.187 & 3.279 & 3.226 & 3.252 \\
\hline & $\operatorname{MME}(\mathbf{U})$ & Relative & 1.000 & 0.834 & 0.837 & 0.825 & 0.849 & 0.835 & 0.842 \\
\hline & & Rank & 7 & 2 & 4 & 1 & 6 & 3 & 5 \\
\hline & & A ctual & 3.741 & 4.268 & 3.824 & 3.828 & 3.808 & 3.675 & 4.004 \\
\hline & MME(O) & Relative & 0.876 & 1.000 & 0.896 & 0.897 & 0.892 & 0.861 & 0.938 \\
\hline & & Rank & 2 & 7 & 4 & 5 & 3 & 1 & 6 \\
\hline & $\%$ & Underestimaton & 51 & 37.2 & 43.3 & 41 & 43.7 & 42.5 & 41 \\
\hline & $\%$ & Overestimation & 49 & 62.8 & 56.7 & 59 & 56.3 & 57.5 & 59 \\
\hline
\end{tabular}


Table 6c. MMEU and MMEO

\begin{tabular}{|c|c|c|c|c|c|c|c|c|c|}
\hline & $\mathbf{R W}$ & HM & MA-12 & WMA-12 & EWMA-12 & ES & REG \\
\hline \multirow{8}{*}{ UK } & \multirow{3}{*}{$\operatorname{MME}(\mathbf{U})$} & A ctual & 2.260 & 1.210 & 1.868 & 1.840 & 1.912 & 1.904 & 1.316 \\
\hline & & Relative & 1.000 & 0.535 & 0.826 & 0.814 & 0.846 & 0.843 & 0.583 \\
\hline & & Rank & 7 & 1 & 4 & 3 & 6 & 5 & 2 \\
\hline & \multirow{3}{*}{ MME(O) } & A ctual & 2.177 & 3.387 & 2.088 & 2.040 & 2.083 & 1.956 & 2.967 \\
\hline & & Relative & 0.643 & 1.000 & 0.616 & 0.602 & 0.615 & 0.577 & 0.876 \\
\hline & & Rank & 5 & 7 & 4 & 2 & 3 & 1 & 6 \\
\hline & $\%$ & Underestimaton & 52.9 & 26.1 & 44.8 & 44.8 & 44.4 & 47.1 & 31.0 \\
\hline & $\%$ & Overestimation & 47.1 & 73.9 & 55.2 & 55.2 & 55.6 & 52.9 & 69.0 \\
\hline \multirow{8}{*}{ US } & \multirow{3}{*}{$\operatorname{MME}(\mathbf{U})$} & A ctual & 2.407 & 1.601 & 2.048 & 1.981 & 2.086 & 2.069 & 176.576 \\
\hline & & Relative & 0.014 & 0.009 & 0.012 & 0.011 & 0.012 & 0.012 & 1.000 \\
\hline & & Rank & 6 & 1 & 3 & 2 & 5 & 4 & 7 \\
\hline & \multirow{3}{*}{$\operatorname{MME}(\mathbf{O})$} & A ctual & 2.406 & 3.585 & 2.163 & 2.170 & 2.119 & 2.015 & 11.222 \\
\hline & & Relative & 0.214 & 0.319 & 0.193 & 0.193 & 0.189 & 0.180 & 1.000 \\
\hline & & Rank & 5 & 6 & 3 & 4 & 2 & 1 & 7 \\
\hline & $\%$ & Underestimaton & 50.2 & 28.7 & 46.4 & 44.1 & 46.4 & 46.7 & 34.5 \\
\hline & $\%$ & Overestimation & 49.8 & 71.3 & 53.6 & 55.9 & 53.6 & 53.3 & 65.5 \\
\hline
\end{tabular}

$M M E(U)$ and $M M E(O)$ are the mean mixed error statistics that penalise the underpredictions and overpredictions more heavily, respectively. Actual is the calculated error statistics. MME(U) and MME(O) actual figures must be multiplied by $10^{-2}$. Relative is the ratio between the actual error statistic of a model and that of the worst performing model. The best performing model has a rank 1.

\section{CONCLUSION}

The present paper employs seven different models, a random walk model, a historical mean model, moving average models, weighted moving average models, exponentially weighted moving average models, an exponential smoothing model, and a regression model, to forecast out-of-sample within-w eek standard deviations in fourteen countries.

In the evaluation of the performances of the models, both symmetric and asymmetric statistics are used. The results show that symmetric statistics, the mean absolute error, the root mean squared error, and the mean absolute percentage error, consistently favour ES model. However, symmetric statistics show that HM and RW models perform poorly.

On the other hand, even though according to asymmetric statistics RW is consistently the worst model, asymmetric statistics do not prove consistent results for the best performing model.

\section{REFERENCES}

[1] A djaoute, K., M. Bruand, and R. Gibson-A sner (1998) On The Predictability of The Stock Market Volatility: Does History Matter? European Financial Management, 4, 293-319.

[2] A kgiray, V. (1989) Conditional Heteroscedasticity in Time Series of Stock Returns: Evidence and Forecasts, J ournal of B usiness, 62, 55-80.

[3] A lexander, C. (1996) V olatility and Correlation Forecasting, in C. A lexander (ed.) The Handbook of Risk M anagement and A nalysis, J ohn Wiley \& Sons, 233-260. 
[4] A ndersen, T. G. and Bollerslev, T. (1997) "Answering the Critics: Y es, A RCH M odels Do Provide Good V olatility Forecasts", N BER W orking Paper Series, 6023, A pril.

[5] B alaban, E. (1998) Forecasting Stock M arket V olatility, Ph.D. Dissertation in Progress, J ohann W ofgang Goethe University, Frankfurt/M ., Germany.

[6] Balaban, E. (1999) Comparative Forecasting Performance of Conditional Volatility Models of Exchange Rates, Unpublished Manuscript, Deutsche Bundesbank, Frankfurt/M ., Germany.

[7] Black, F. (1976) Studies of Stock Price V olatility Changes, Proceeedings of the 1976 Meetings of the American Statistics Association, Business and Economics Statitics Section, 177-81.

[8] Brailsford, T. J. and R. W. Faff (1996) An Evaluation of Volatility Forecasting Techniques, J ournal of Banking and Finance, 20, 419-438.

[9] Brooks, C., Burke, S. P., 1998. Forecasting exchange rate volatility using conditional variance models selected by information criteria, Economics Letters 61, 273-278.

[10] Diebold, F. X. and J. A. Lopez (1996) Forecast Evaluation and Combination, in G. S. $M$ addala and $C$.

[11] R. Rao (eds.) Handbook of Statistics, Volume 14: Statistical Methods in Finance. North-H olland, A msterdam.

[12] Dimson, E. and P. M arsh (1990) V olatility Forecasting Without D ata-Snooping, J ournal of B anking and Finance, 14, 399-421.

[13] Figlewski, S. (1997) Forecasting Volatility, Financial Markets, Institutions \& Instruments, 6, Number 1.

[14] French, K. R., G. W. Schwert and R. Stambaugh (1987) Expected Stock Returns and V olatility, J ournal of Financial Economics, 19, 3-29.

[15] Taylor, S. J. 1987 Forecasting the V olatility of Currency Exchange Rates, Internatioal J ournal of Forecasting, 3, 159-170.

[16] Tse, Y . K. (1991) Stock Returns V olatility in the Tokyo Stock Exchange, Japan and the W orld Economy, 3, 285-298.

[17] Tse, S. H. and K. S. Tung (1992) Forecasting V olatility in the Singapore Stock M arket, A sia Pacific J ournal of M anagement, 9, 1-13.

[18] West, K. D., Cho, D., 1995. The predictive ability of several models of exchange rate volatility, J ournal of Econometrics 69, 367-391. 